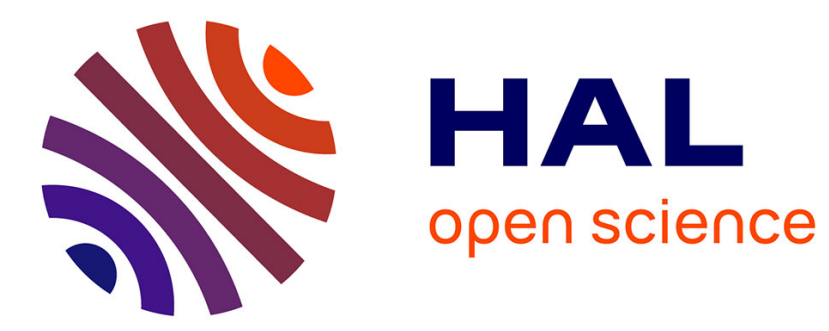

\title{
Parametrization of drop size distribution with rain rate.
}

\author{
A.D. Ochou, A. Nzeukou, Henri Sauvageot
}

\section{To cite this version:}

A.D. Ochou, A. Nzeukou, Henri Sauvageot. Parametrization of drop size distribution with rain rate.. Atmospheric Research, 2007, 84 (1), pp.58-66. 10.1016/j.atmosres.2006.05.003 . hal-00519464

\section{HAL Id: hal-00519464 \\ https://hal.science/hal-00519464}

Submitted on 25 Nov 2020

HAL is a multi-disciplinary open access archive for the deposit and dissemination of scientific research documents, whether they are published or not. The documents may come from teaching and research institutions in France or abroad, or from public or private research centers.
L'archive ouverte pluridisciplinaire HAL, est destinée au dépôt et à la diffusion de documents scientifiques de niveau recherche, publiés ou non, émanant des établissements d'enseignement et de recherche français ou étrangers, des laboratoires publics ou privés. 


\title{
Parametrization of drop size distribution with rain rate
}

\author{
Abe Delfin Ochou ${ }^{\mathrm{a}}$, Armand Nzeukou ${ }^{\mathrm{b}}$, Henri Sauvageot ${ }^{\mathrm{c}, *}$ \\ ${ }^{\text {a }}$ Université de Cocody, Abidjan, Côte d'Ivoire \\ b IUT Fotso Victor, Université de Dschang, Dschang, Cameroun \\ ${ }^{\mathrm{c}}$ Laboratoire d'Aérologie, Observatoire Midi-Pyrénées, Université Paul Sabatier, 65300 Lannemezan, France
}

\begin{abstract}
Because the rain rate $R$ is easier to observe than the drop size distribution (DSD), it is useful to express the DSD as a function of $R$ only, i.e. $N(D, R)$. Disdrometer data from four sites in West Africa are used to compare observed DSDs with fitting to a lognormal function in which the three parameters $X_{i}$, with $i=1,2,3$, are expressed as functions of $R$ only. Observed DSDs are found well represented by such $N(D, R)$ function. Writing the $N(D, R)$ moments for a calculation of useful physical quantities, such as water content $M$, rain rate, or radar reflectivity factor $\mathrm{Z}$, raises constraints of self consistency of the various equations. Modifying the analytical form of DSD in order to take into account the constraint of self-consistency is not found to increase significantly the quality of the DSD fitting with respect to the direct use of $X_{i}(R)$ in the distribution, ignoring the lack of self-consistency. Then $Z-R$ relations obtained by direct regression of observed data are compared with the relations derived analytically from $N(D, R)$ and the expressions $X_{i}(R)$ observed in each site. The two groups of relations compare very well.
\end{abstract}

Keywords: Rain drop size distribution; Lognormal distribution; Rainfall; Radar reflectivity; West Africa

\section{Introduction}

Rain drop size distribution (DSD) and its moments are used in the discussion of numerous scientific or technical topics concerning teledetection and environmental sciences. For example, microwave radiometric brightness temperature, radar reflectivity factor, and electromagnetic attenuation depend on the DSD (Coppens and Haddad, 2000; Iguchi et al., 2000), as well as ground erosion and atmospheric pollution scavenging by rain (e.g. Young, 1993). Yet, DSD is not frequently measured, only in sparse locations mostly in hospitable areas of mid-latitude and at some rare points at tropical latitude.

\footnotetext{
* Corresponding author.

E-mail address: sauh@aero.obs-mip.fr (H. Sauvageot).
}

A pluviometric parameter easier to estimate than the DSD, as much from space as from a ground sensor network, is the rain rate $R$. The tools for direct rain rate measurements are, at the ground, tipping-bucket rain gauges and radars, and, from space, cloud observations in visible and infrared (IR), as well as passive and active, microwaves (Barrett and Martin, 1981; Huffman et al., 1997; Kebe et al., 2005). There are also many data on the distribution of cumulative rainfall and precipitation duration over the earth from which information on the "climatic" mean rain rate $\mu_{R}$ can be obtained (International Telecommunication Union, 2001) using rainfall disaggregation models (Molnar and Burlando, 2005).

The ergodic character of precipitation fields observed in some areas of mid and tropical latitudes (Nzeukou and Sauvageot, 2002) strengthens the validity of $\mu_{R}$ as a 
parameter representative of the rain rate field. Knowing $\mu_{R}$, the probability distribution function (pdf) of $R$, or $P$ $(R)$, can be deduced. In fact, $P(R)$ can be represented by a lognormal distribution (e.g. Atlas et al., 1990; Sauvageot, 1994; Nzeukou and Sauvageot, 2002, among others). Such a distribution, written $\Lambda\left(\mu_{R}, \sigma_{R}^{2}\right)$, depends on two parameters, the mean $\mu_{R}$ and the variance $\sigma_{R}^{2}$ of $R$ (e.g. Crow and Shimizu, 1988) with, in between, the linear relation $\sigma_{R}=\sqrt{5 \mu_{R}}$ (Sauvageot, 1994; Nzeukou and Sauvageot, 2002). In other words, the mere knowledge of $\mu_{R}$ enables the determination of $P(R)$. The distribution of $R$ over the earth can thus be considered as rather well known and documented. In such conditions, being able to write it as a function of only the $R$ parameter is of obvious interest, so as to describe the DSD over the whole earth.

Representations of the DSD with analytical functions were addressed in numerous papers. The most current forms are the exponential function, the complete or modified gamma function, the lognormal function, and some scaled or normalized formulations trying to account for all previous fitting functions. These functions depend on two or three parameters. Some authors have proposed to write these parameters as functions of $R$, that is $X_{i}(R)$, where $X_{i}$ is the considered parameter (Marshall and Palmer, 1948; Ulbrich, 1983; Feingold and Levin, 1986; Sauvageot and Lacaux, 1995; Sempere-Torres et al., 1994, among others). However, few of them have discussed the climatic and geographic variability of the $X_{i}(R)$ functions or presented comparisons between fitted and observed distributions to validate the proposed formulation.

In applications using DSDs, useful quantities are often derived from moments of the DSD, notably the rain rate, water content $M$, and radar reflectivity factor Z. Derivation of some DSD moments raises a problem of self consistency between the various relations, and self consistency generates some constraints on the parameters of $X_{i}(R)$ (Sempere-Torres et al., 1994; Lee et al., 2004, among others). However, few authors have bothered to compare the results obtained by ignoring or considering these constraints.

The goal of the present paper is to analyse the variability of $X_{i}(R)$ relations for West Africa from a wide data sample gathered at four sites representative of various climates of this region. The DSDs computed from the $X_{i}(R)$ relations are compared with the observed DSDs, with and without the self consistency constraints. The $Z-R$ relations analytically derived from $X_{i}(R)$ s are compared with the direct regression of the observed values.

\section{Theoretical background}

\subsection{Functional forms of the DSD}

Numerous authors have discussed the fitting of the DSD with analytical functions. Marshall and Palmer (1948) have proposed the exponential form:

$N(D)=N_{0} \exp (-\lambda D)$,

where $N(D)$ is the number (usually in $\mathrm{m}^{-3} \mathrm{~mm}^{-1}$ ) of drops having an equivalent spherical diameter $D$ (in $\mathrm{mm}$ ) by unit volume, for a diameter interval of $1 \mathrm{~mm}$. $N_{0}$ and $\lambda$ are two parameters that Marshall and Palmer (1948) propose to write $N_{0}=8 \times 10^{3} \mathrm{~mm}^{-1} \mathrm{~m}^{-3}$ and $\lambda=4.1 \mathrm{R}^{-0.21} \mathrm{~mm}^{-1}$ with $R$ in $\mathrm{mm} \mathrm{h}^{-1}$. Replacing $N_{0}$ and $\lambda$ in Eq. (1) enables the writing of an expression of $N(D)$ with only $R$ as parameter. This distribution is widely used due to simplicity and because it fits well mid-latitude DSDs which have a low to moderate intensity.

For tropical latitudes, where heavy rain rates are common (mean rain rate $\mu_{R}$ is 6 to 7 times higher at tropical latitudes than at mid-latitudes - e.g. Sauvageot, 1994), form (1) is not convenient for two reasons. First, it is observed that for $R$ higher than 10-20 $\mathrm{mm} \mathrm{h}^{-1}$, the DSD slope, for $D$ larger than the modal value (1-2 mm), becomes almost constant (e.g. Mueller and Sims, 1966; Pasqualucci, 1982; Sauvageot and Lacaux, 1995) while the Marshall-Palmer distribution assumes that $\lambda$ decreases as $R$ increases. The constant slope observed in heavy tropical rain expresses the evolution of the DSD towards an equilibrium form in which the shape of DSDs does not change any more. The DSD is then the product of a generic shape $\varphi(D)$ by rain rate (List, 1988; Hu and Srivastava, 1995). Secondly, the number of small drops $(D<1-2 \mathrm{~mm})$ is smaller than that corresponding to the exponential form (1) for the same rain rate, for various causes including evaporation. That is why tropical DSDs are usually fitted with three parameter functions, the most frequently used being the gamma complete or modified and the lognormal forms, as recalled above. Comparative studies show that these three distributions lead to very similar results to fit the observed tropical DSDs (e.g. Nzeukou et al., 2004). That is why, in the present paper, only one of the three is considered, the lognormal one. This distribution is preferred because its parameters have a simple geometric interpretation and the moments can be written in the form of a product of three terms, each of 
them being a function of only one of the three parameters.

The lognormal distribution is:

$N(D)=\frac{N_{\mathrm{T}}}{(2 \pi)^{0.5}(\operatorname{Ln} \sigma) D} \exp \left[-\frac{\operatorname{Ln}^{2}\left(D / D_{g}\right)}{2 \operatorname{Ln}^{2} \sigma}\right]$,

where $\mathrm{Ln}$ is the natural logarithm, $N_{\mathrm{T}}\left(=X_{1}\right)$ is the total drop number per unit volume, $D_{\mathrm{g}}\left(=X_{2}\right)$ is the geometric mean diameter and $\sigma\left(=X_{3}\right)$ is the geometric standard deviation, namely:

$N_{\mathrm{T}}=\int_{0}^{\infty} N(D) d D$,

$\operatorname{Ln} D_{\mathrm{g}}=\overline{\operatorname{Ln} D}$,

$\operatorname{Ln}^{2} \sigma=\left(\overline{\operatorname{Ln} D-\operatorname{Ln} D_{\mathrm{g}}}\right)^{2}$.

To fit a lognormal function to an observed distribution, the three parameters $N_{\mathrm{T}}, D_{\mathrm{g}}$, and $\sigma$, are simply calculated from their definition formulae (3)-(5). In the presence of a truncation of the observed DSD, a truncation correction can be applied if necessary, using the method proposed by Cohen (1991), which gives very good results.

DSDs are observed with sizing spectrometers such as disdrometers (cf. Section 3). From each DSD, the three $X_{i}$ and the corresponding rain rate $R$ can be numerically computed, providing three ensembles of couple $X_{i}-R$ (with $i=1,2,3$ ). These ensembles can be used to analyse relations $X_{i}-R$. Such relations have been computed for DSDs observed in various areas in the world, for example by Feingold and Levin (1986) or Sauvageot and Lacaux (1995). Authors found that $N_{\mathrm{T}}$ and $D_{\mathrm{g}}$ can be represented by power functions, namely:

$N_{\mathrm{T}}=\alpha R^{\beta}$,

and

$D_{\mathrm{g}}=\gamma R^{\delta}$

and that $\sigma$ is linearly related to $R$, namely:

$\sigma=\eta R+\xi$

where $\alpha, \beta, \gamma, \delta, \eta$, and $\xi$ are coefficients depending on the DSD climatic particularities at the observation site.
In (8), the linear coefficient $\eta$ is so low that $\sigma$ is sometimes approximated by $\sigma=\xi$. Values of these various coefficients are estimated by fitting.

If (6) and (7) are used in (2) with $\sigma=\xi$, there results an expression of $N(D)$ with only $R$ as parameter:

$N(D, R)=\frac{\alpha R^{\beta}}{(2 \pi)^{0.5}(\operatorname{Ln} \xi) D} \exp \left[-\frac{\operatorname{Ln}^{2}\left(D \gamma^{-1} R^{-\delta}\right)}{2 \operatorname{Ln}^{2} \xi}\right]$

one of the goals of the present paper is to see if (9) is a correct fitting for observed DSD.

\subsection{Integrals parameters and $Z-R$ relation}

The $\mathrm{n}$ order moment of $N(D)$ is defined as:

$m_{n}=\int_{0}^{\infty} D^{n} N(D) d D$.

Using (9) in (10) and integrating gives:

$m_{n}=\left[\alpha \gamma^{n} \exp \left(\frac{n^{2}}{2} \operatorname{Ln}^{2} \xi\right)\right] R^{n \delta+\beta}$,

which shows that the moments of $N(D)$ can be written as power functions of $R$. Since $R$ is lognormally distributed, moments are also lognormally distributed (e.g. Crow and Shimizu, 1988).

From (10), some useful integral rain parameters can be written, notably, among others, radar reflectivity factor:

$$
\begin{aligned}
Z & =\int_{0}^{\infty} D^{6} N(D) \mathrm{d} D=m_{6} \\
& =\left[\alpha \gamma^{6} \exp \left(18 \operatorname{Ln}^{2} \xi\right) \mid R^{\beta+6 \delta},\right.
\end{aligned}
$$

and rain rate:

$R=\frac{\pi}{6} \int_{0}^{\infty} D^{3} N(D) v(D) \mathrm{d} D$,

where $v(D)=\mathrm{aD}^{0.67}$ is the terminal velocity of raindrops in still air and a is a coefficient $\left(\mathrm{a}=3.6 \times 10^{-3}\right.$ - Atlas and Ulbrich, 1977), that is:

$$
\begin{aligned}
R & =\frac{\pi}{6} \mathrm{a} m_{3.67} \\
& =\left[\frac{\pi}{6} \mathrm{a} \alpha \gamma^{3.67} \exp \left(\frac{3.67^{2}}{2} L n^{2} \xi\right)\right] R^{\beta+3.67 \delta} .
\end{aligned}
$$




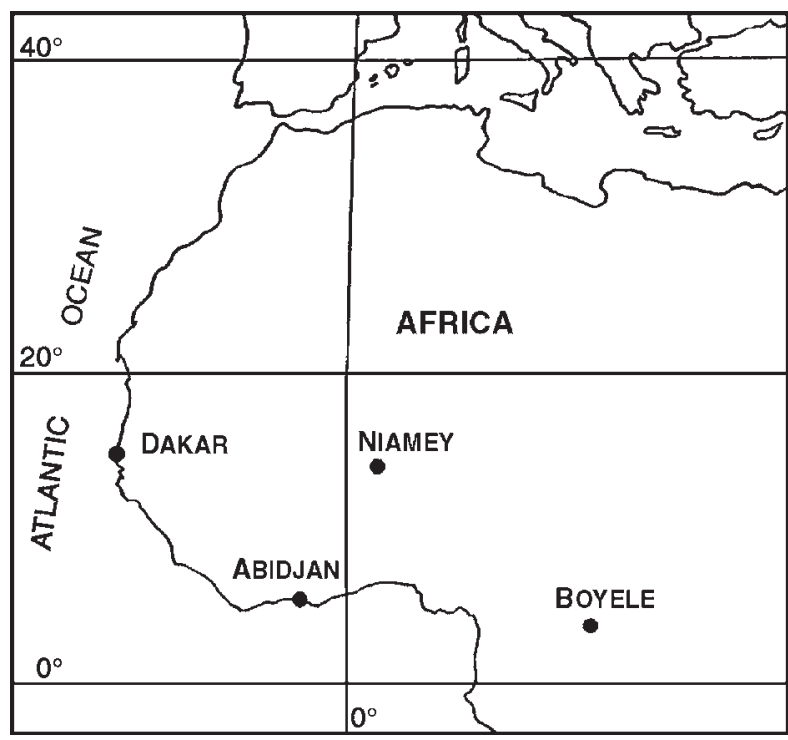

Fig. 1. Location of the data collection sites.

Eliminating $\xi$ between (12) and (13) as done in Nzeukou et al. (2004), leads to the relation:

$Z=A R^{b}$

with:

$A=5.6 \times 10^{5} \alpha^{-1.68} \gamma^{-3.82}$

$b=2.67-1.68 \beta-3.82 \delta$.

\subsection{Self consistency constraints}

As discussed by various authors, notably SempereTorres et al. (1994), self consistency of (13), that

Table 1

Data base

\begin{tabular}{|c|c|c|c|}
\hline Location & $\begin{array}{l}\text { Coordinates } \\
\text { altitude }\end{array}$ & Observing period & $\begin{array}{l}\text { Number of } \\
\text { DSD in the } \\
\text { sample }\end{array}$ \\
\hline $\begin{array}{l}\text { Abidjan } \\
\quad \text { (Ivory Coast) }\end{array}$ & $\begin{array}{l}5^{\circ} 25 \mathrm{~N}- \\
4^{\circ} \mathrm{W} 40 \mathrm{~m}\end{array}$ & $\begin{array}{l}1986 \\
\text { (June; Sept. to Dec.) } \\
1987 \text { (Jan. to Dec.) } \\
1988 \text { (Jan. to June) }\end{array}$ & 24875 \\
\hline $\begin{array}{l}\text { Dakar } \\
\quad(\text { Sénégal) }\end{array}$ & $\begin{array}{l}14^{\circ} 34 \mathrm{~N}- \\
17^{\circ} 29 \mathrm{~W} 30 \mathrm{~m}\end{array}$ & $\begin{array}{l}1997 \text { (June to Sept.) } \\
1998 \text { (June to Sept.) } \\
2000 \text { (June to Sept.) }\end{array}$ & 10461 \\
\hline Niamey (Niger) & $\begin{array}{l}13^{\circ} 30 \mathrm{~N}-2^{\circ} 10 \\
\text { E } 220 \mathrm{~m}\end{array}$ & $\begin{array}{l}1989 \text { (Jul. to Sept.) } \\
1988 \text { (May to Jul.; } \\
\text { Sept. to Dec.) }\end{array}$ & 3147 \\
\hline \multirow[t]{2}{*}{ Boyélé (Congo) } & $\begin{array}{l}2^{\circ} 50 \mathrm{~N}-18^{\circ} 04 \\
\text { E } 330 \mathrm{~m}\end{array}$ & 1989 (Mar. to June) & 22223 \\
\hline & & Total & $60706 \mathrm{~min}$. \\
\hline
\end{tabular}
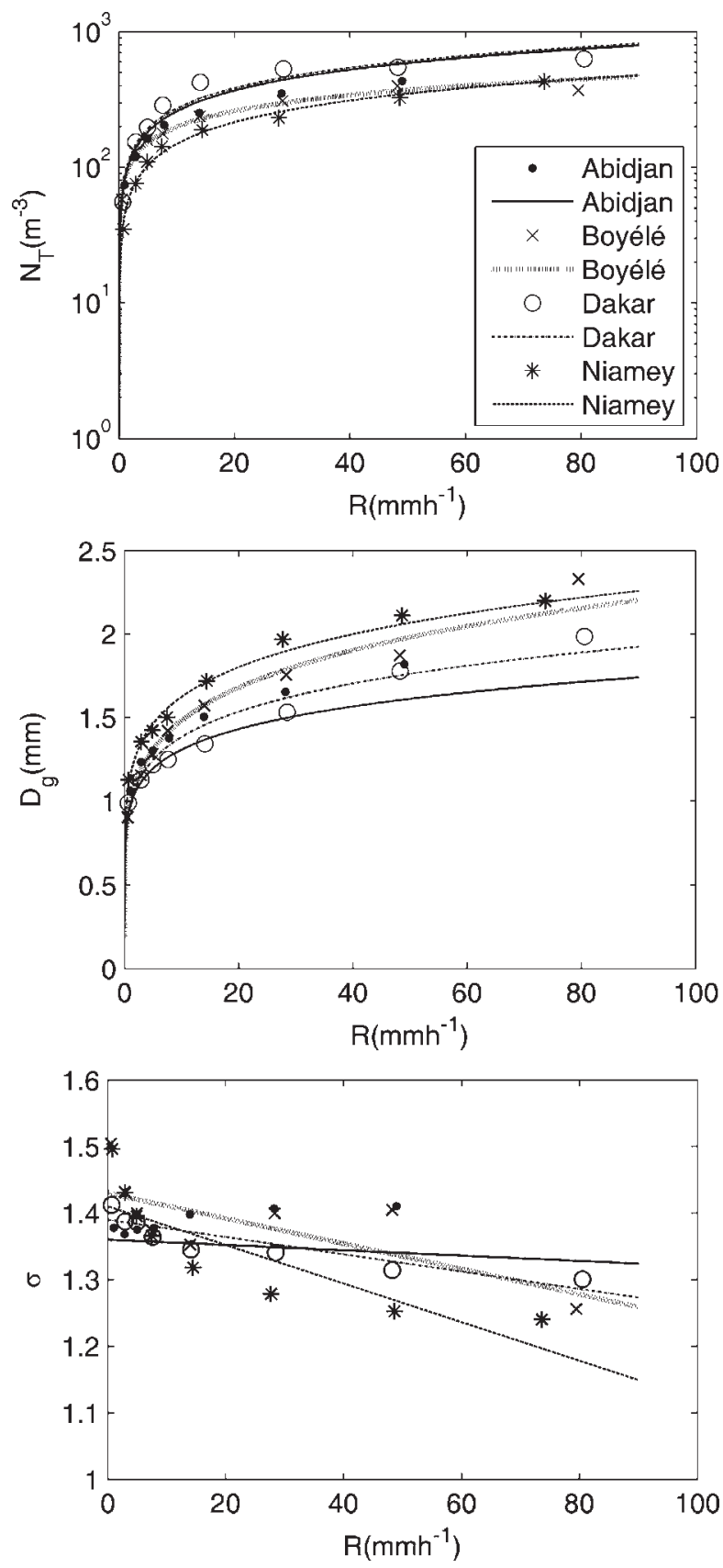

Fig. 2. Variation of the lognormal distribution parameters $N_{\mathrm{T}}, D_{\mathrm{g}}$, and $\sigma$ as a function of $R$ for the four sites Abidjan (Abi), Boyélé (Boy), Dakar (Dak), and Niamey (Nia).

is equality of the two members of the equation, implies:

$\beta+3.67 \delta=1$

$\frac{\pi}{6} a \alpha \gamma^{3.67} \exp \left(\frac{3.67^{2}}{2} \operatorname{Ln}^{2} \xi\right)=1$. 
Taking $\xi$ as a constant, the four Eqs. (15)-(18) enable the calculation of the expression of the four coefficients $\alpha, \beta$, $\gamma$, and $\delta$ as a function of $A$ and $b$ conveying the self consistency constraints. Using these expressions in (9) leads to a new $N(D, R)$ relation fitting the observed distributions and satisfying the self consistency constraints. To do that, it is indispensable to first calculate $A$ and $b$ by regressing the couples $Z-R$ for the corresponding data set. It is clear that the self consistency expression of the four parameters can be obtained by regressing $R$ with another integral parameter than $\mathrm{Z}$.

To sum up, having climatologically representative computed values of the parameters of the three $X_{i}(R)$ relations from a data set of observed DSDs, it is possible:

- to use these relations in the $N(D)$ function (2) and obtain a $N(D, R)$ expression having $R$ as the only parameter, that is $(9)$,

- to constrain (9) to satisfy self consistency by replacing the parameters of $X_{i}(R)$ by new values obtained from the self consistency equations. To that purpose, the climatic coefficient of the $Z-R$ relation (obtained by regression on a representative data set) must be used.

To discuss the interest of these $N(D)$ expressions, Section 4 compares averaged DSDs observed at each site, DSDs given by (9), and DSDs obtained by (9) and satisfying, in addition, the self consistency constraints.

For the $Z-R$ relations, the parameters obtained by direct regression of the data must be compared with those obtained by combining $\mathrm{Z}$ and $R$ deduced from the moments of the DSD function of $R$ only. This is done in Section 4 .

\section{Data}

The data were collected at four West African sites (Fig. 1 and Table 1), representing each a different type of climate: coastal and Sahelian for Dakar, coastal and equatorial for Abidjan, continental and Sahelian for Niamey, and continental and equatorial for Boyélé.

(1) Dakar is located at the headland of Cape Verde. The climate of this area is Sahelian with a rainy season reduced to about 3 months, from early July to late September, when the intertropical convergence zone (ITCZ) is higher than $13^{\circ} \mathrm{N}$. Radar and satellite observations show that most of the rainbearing systems crossing this area are organized as squall lines that become weaker and then disappear as they migrate from land to sea and move over the nearby ocean. However, inversely, a few systems grow stronger, progress over the sea and could be involved in the genesis of the hurricanes of the west tropical Atlantic (e.g., Sall and Sauvageot, 2005). The Dakar area is flat over several hundred kilometres, with an altitude lower than $200 \mathrm{~m}$. The mean annual cumulative rainfall at Dakar is about $500-600 \mathrm{~mm}$, with a strong meridional gradient.

(2) Abidjan is in southern Ivory Coast, on the Guinea Gulf coast. In this area, it is possible to clearly distinguish a long rainy season from March to mid-July, associated with the northward migration of the intertropical convergence zone (ITCZ), and a short rainy season from mid-September to late November, associated with the southward migration of the ITCZ. The mean annual total rainfall is about $1800 \mathrm{~mm}$. The region is flat.

(3) Niamey is in southwestern Niger. The rainy season lasts about 3 months, from early July to late September. Niamey is situated in the middle of the Sahelian Sudanese strip. The mean annual total rainfall is about $500 \mathrm{~mm}$. The rainy season is associated with the northward move of the ITCZ. The area is very flat. The most significant raingenerating events are organized in squall lines.

Table 2

Parameters of $N_{\mathrm{T}}, D_{\mathrm{g}}$ and $\sigma$ versus $R$

\begin{tabular}{|c|c|c|c|c|c|c|c|c|c|c|c|c|c|}
\hline \multirow[t]{3}{*}{ Sites } & \multicolumn{5}{|c|}{$N_{\mathrm{T}}=\alpha R^{\beta}$} & \multicolumn{5}{|c|}{$D_{\mathrm{g}}=\gamma R^{\delta}$} & \multicolumn{3}{|l|}{$\sigma$} \\
\hline & \multicolumn{2}{|l|}{$\alpha$} & \multicolumn{2}{|l|}{$\beta$} & \multirow{2}{*}{$\begin{array}{l}\text { Coef } \\
\text { corr } \\
\text { Regr }\end{array}$} & \multicolumn{2}{|l|}{$\gamma$} & \multicolumn{2}{|l|}{$\delta$} & \multirow{2}{*}{$\begin{array}{l}r \text { for } \\
\text { Regr }\end{array}$} & & & \\
\hline & $\mathrm{SC}$ & Regr & $\mathrm{SC}$ & Regr & & $\mathrm{SC}$ & Regr & $\mathrm{SC}$ & Regr & & $\mathrm{SC}$ & Regr & $r$ \\
\hline Abidjan & 79 & 80 & 0.56 & 0.51 & 0.98 & 1.00 & 0.97 & 0.12 & 0.13 & 0.97 & 1.34 & $\sigma=1.36-0.0004 R$ & 0.35 \\
\hline Boyélé & 72 & 81 & 0.46 & 0.39 & 0.98 & 0.97 & 0.98 & 0.15 & 0.18 & 0.98 & 1.41 & $\sigma=1.43-0.0019 R$ & 0.54 \\
\hline Dakar & 73 & 86 & 0.62 & 0.50 & 0.98 & 0.96 & 0.98 & 0.10 & 0.15 & 0.98 & 1.41 & $\sigma=1.39-0.0013 R$ & 0.73 \\
\hline Niamey & 59 & 44 & 0.56 & 0.53 & 0.99 & 0.95 & 1.15 & 0.12 & 0.15 & 0.99 & 1.49 & $\sigma=1.41-0.0029 R$ & 0.72 \\
\hline West Africa & 71 & 78 & 0.54 & 0.44 & 0.98 & 0.97 & 1.01 & 0.12 & 0.16 & 0.99 & 1.41 & $\sigma=1.41-0.0004 R$ & 0.15 \\
\hline
\end{tabular}

$\mathrm{SC}$ is for self-consistency, Regr for regression and $r$ is the correlation coefficient. 

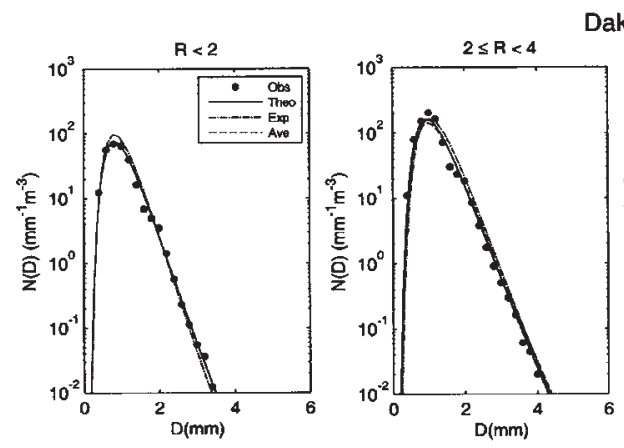

Dakar
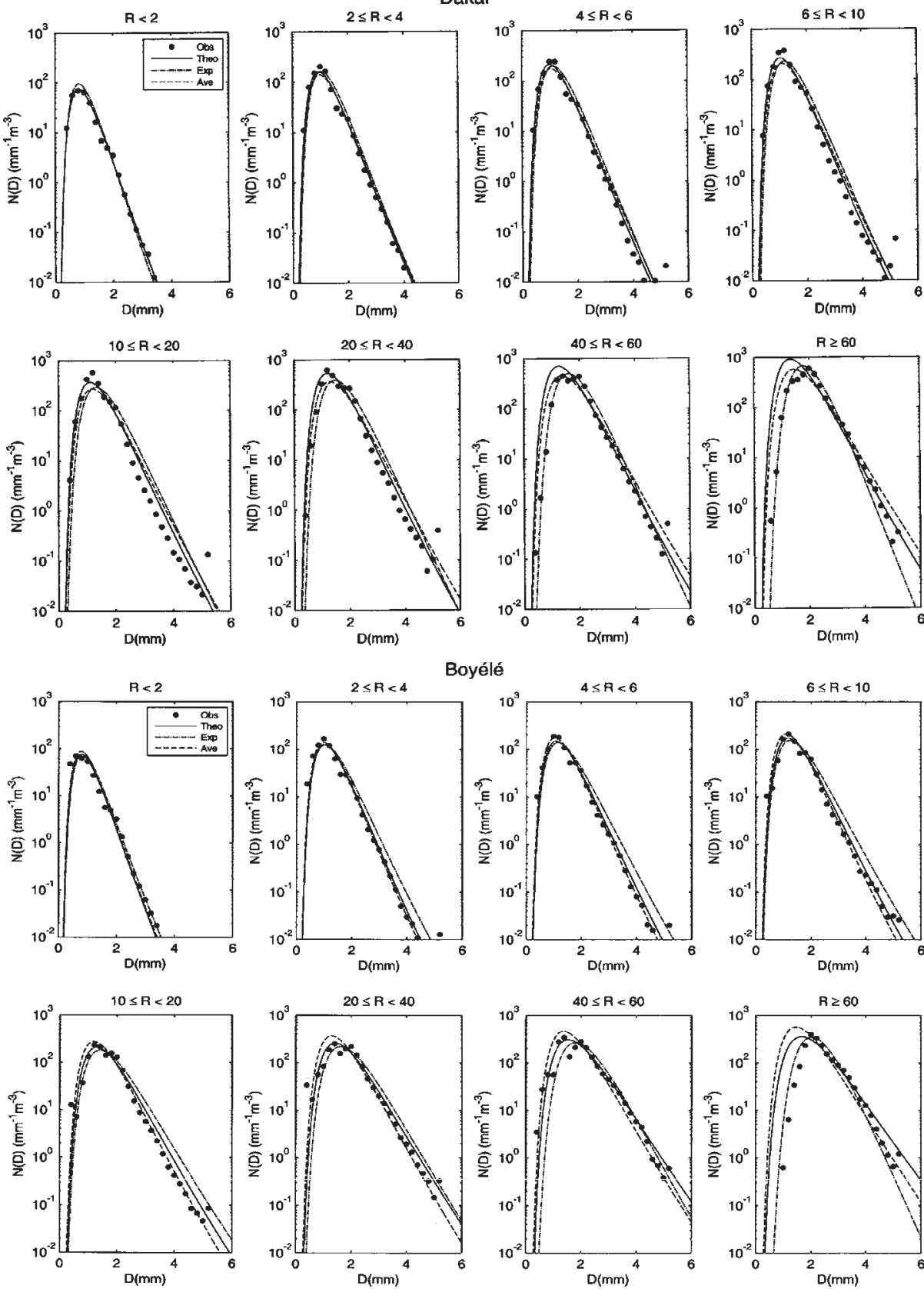

Fig. 3. Averaged DSDs for eight classes of rain rate $R$. Dots are the observed data points for the classes of JWD, "Theo" is for curves fitted with the self consistency constraints, "Exp" is for the curves fitted from the $N_{\mathrm{T}}-R$ and $D_{\mathrm{g}}-R$ relations, and "Ave" is for the curves fitted with the self consistency constraints applied to the data set resulting from the merging of the four sites. Upper panel is for the Dakar site and lower panel for the Boyélé one.

(4) Boyélé is in northern Congo. It is located in the upper basin of the Oubangui River in a locally flat region. The mean annual pluviometry is about $1000 \mathrm{~mm}$. The rainy season lasts from early March to late November. The measurement station was situated in the Pygmy area, in a vast clearing surrounded by primary equatorial forest. The main precipitating systems are also organized in squall lines there.

DSDs were observed with a Joss and Waldvogel (1969) disdrometer (JWD hereinafter). The JWD 
enables measurements of the size distribution of raindrops by converting the mechanical moments of falling drops into electric pulses. The performances and limitations of this widely used sensor are well known and have been discussed in many papers (e.g. Joss and Waldvogel, 1969; Sheppard, 1990; Sheppard and Joe, 1994; Sauvageot and Lacaux, 1995; Tokay et al., 2001; also see online at http://www.distromet.com). Only drops with an equivalent spherical diameter $D$ larger than $0.3 \mathrm{~mm}$ are detected. In the JWD used, the pulses are converted into eight-bit numbers and sorted according to 25 size classes, all with the same width $(\Delta D=0.2 \mathrm{~mm})$, covering diameters ranging from 0.3 to $5.3 \mathrm{~mm}$. It is acknowledged that, in heavy rainfall, small drops $(D<1 \mathrm{~mm})$ are not accurately counted with JWD because of instrumental shortcomings. However, Sauvageot and Lacaux (1995) present arguments showing that the relatively low number of small drops usually observed in tropical rain is not far from reality when the JWD is carefully used at a site from which the sources of microphonic noise are removed. The data were processed for a (partial) correction of the error due to the dead time of the instrument after the sampling area is hit by a drop, using the method proposed by the manufacturer. Details on the JWD measurement limits

Table 3

Root mean square (RMS) of differences between observed and calculated drop size distributions

\begin{tabular}{|c|c|c|c|c|c|c|c|c|}
\hline \multirow{2}{*}{$\begin{array}{l}\text { Class of } \\
\text { rain rate } \\
\left(\mathrm{mm} \mathrm{h}^{-1}\right)\end{array}$} & \multicolumn{2}{|c|}{ Abidjan } & \multicolumn{2}{|c|}{ Boyélé } & \multicolumn{2}{|c|}{ Dakar } & \multicolumn{2}{|c|}{ Niamey } \\
\hline & $\mathrm{SC}$ & Regr & $\mathrm{SC}$ & Regr & $\mathrm{SC}$ & $\mathrm{I}$ & $\mathrm{C}$ & $\Gamma$ \\
\hline \multicolumn{9}{|c|}{ RMS differences for each site } \\
\hline$R<2$ & 8 & 8.4 & 8.8 & 9.2 & 2.2 & 7 & & 4.6 \\
\hline$\leq R$ & 15 & 14 & & 1 & & 1 & .5 & 7.7 \\
\hline$\leq R$ & 19.8 & 16 & 1 & 17.4 & 15.2 & 2 & .4 & 13 \\
\hline$\leq R$ & 24.9 & 17 & & 15 & 31.2 & 47 & 9 & 18.5 \\
\hline $0 \leq R$ & 45 & 29.6 & 18.2 & 19.4 & 4 & 78 & 50.2 & 14.6 \\
\hline $0 \leq R<40$ & 74.7 & 48.1 & & 24.3 & 56.7 & 76.4 & 86.9 & 19.8 \\
\hline $0 \leq R<60$ & 117 & 77.6 & 43.3 & 56.1 & 142 & 42.2 & 124 & 25 \\
\hline$R \geq 60$ & 225 & 164 & 98.2 & 39.7 & 244 & 72.6 & 157 & 40.4 \\
\hline
\end{tabular}

RMS differences using the merged West Africa data set

$\begin{array}{lllllllll}R<2 & 7 & 6.4 & 9.2 & 10.3 & 2.3 & 4.7 & 13 & 15.9 \\ 2 \leq R<4 & 13.8 & 12.7 & 8.9 & 15.9 & 18.7 & 25.2 & 23.8 & 20.4 \\ 4 \leq R<6 & 17.1 & 20.4 & 10 & 16.5 & 22 & 33.4 & 26.7 & 18.1 \\ 6 \leq R<10 & 18.1 & 26.2 & 20.9 & 14.5 & 46.4 & 64.8 & 32.2 & 17.7 \\ 10 \leq R<20 & 22.5 & 28 & 35.9 & 15.6 & 73.6 & 105 & 60.4 & 27 \\ 20 \leq R<40 & 37.5 & 39.3 & 68.2 & 24 & 64 & 112 & 103 & 47.2 \\ 40 \leq R<60 & 65.7 & 43.8 & 89.4 & 46.9 & 63.2 & 74.7 & 141 & 60.1 \\ R \geq 60 & 147 & 66 & 189 & 74.5 & 114 & 72 & 173 & 72.7\end{array}$

$\mathrm{SC}$ is for self-consistency, Regr is for regression - Upper panel gives RMS between calculated and observed DSDs for each site - Lower panel gives RMS between calculated DSDs for each site with observed curves corresponding to the merged West African data sample.
Table 4

Coefficient of $Z=\mathrm{AR}^{\mathrm{b}}$ relation

\begin{tabular}{lllllll}
\hline Site & \multicolumn{2}{l}{ Observed } & & & \multicolumn{2}{l}{$\begin{array}{l}\text { Calculated } \\
\text { with (12) }\end{array}$} \\
\cline { 2 - 3 } & $A$ & $\mathrm{~b}$ & $\mathrm{r}$ & & $\mathrm{A}$ & $\mathrm{b}$ \\
\hline Abidjan & 369 & 1.28 & 0.98 & & 417 & 1.32 \\
Dakar & 368 & 1.24 & 0.94 & & 355 & 1.26 \\
Niamey & 508 & 1.28 & 0.95 & & 591 & 1.21 \\
Boyélé & 389 & 1.34 & 0.96 & & 393 & 1.33 \\
West Africa & 390 & 1.29 & 0.95 & & 373 & 1.32 \\
\hline
\end{tabular}

can be found in the above-cited references. The measurement time span of a DSD is $1 \mathrm{~min}$.

\section{Results}

\subsection{Relations $X_{i}(R)$}

Fig. 2 and Table 2 present the results on the fitting of functional relations between $N_{\mathrm{T}}, D_{\mathrm{g}}$ and $\sigma$ versus $R$, for the four sites. Eight classes of rain rate were considered and the fittings were performed on the eight values. In Fig. 2, the experimental data points are plotted and the fittings to power functions are drawn, without considering the self consistency constraints. Table 2 gives the values of the parameters of the $X_{i}(R)$ relations obtained: (a) by direct regression of the observed couple $N_{\mathrm{T}}-R$ and $D_{\mathrm{g}}-R$, (b) deduced from the self consistency constraints. The values for "West Africa" were obtained by processing all data sets as a single sample. For $N_{\mathrm{T}}$, the linear coefficient $\alpha$ is higher for observed curves than for calculated ones. It is the reverse for the power coefficient $\beta$. Both scattering and difference between observed and calculated values are smaller for $D_{\mathrm{g}}$ than for $N_{\mathrm{T}}$, which is not surprising since $D_{\mathrm{g}}$ results from an average. $\sigma$ is linear with an intercept wide with respect to the variable term. The correlation coefficient is small for that reason. All these values compare well with the results of other authors (Feingold and Levin, 1986).

\subsection{DSD shape}

Fig. 3 and Table 3 present the results of the retrieval of the DSD shape. Fig. 3 shows the DSDs for eight classes of rain rate. On each panel appear the observed data points corresponding to the classes of diameter of the disdrometers, as well as three fitted curves: one calculated from the formulae satisfying self consistency (Theo), one deduced from the regression $N_{\mathrm{T}}-R, D_{\mathrm{g}}-R$, and $\sigma=\xi$ for each site (Exp), and the third one calculated for the self consistency constraints obtained from the general data set resulting from the merging of 
the data sets of the four sites (Ave). The curves for only two sites are presented, Dakar and Boyélé, which are coastal and continental respectively. The curves for the two other sites are similar to that of Fig. 3. What can be seen in Fig. 3 is that the three curves fit very well the data points. Notably, the curves obtained by using the $N_{\mathrm{T}}-R, D_{\mathrm{g}}-R$, and $\sigma=\xi$ relations in $N(D)$ lead to a satisfactory fitting. For Boyélé, the best result corresponds to the Ave curves, that is the one with self consistency applied to the merged data set. Table 3, upper panel, gives the RMS (root mean square) differences between the observed data points and the fitted curves for the DSD of the four sites and for the eight rain rate classes, that is:

$\mathrm{RMS}=\left[\frac{1}{25} \sum_{i=1}^{25}\left(N_{i_{\mathrm{observed}}}-N_{i_{\mathrm{fitted}}}\right)^{2}\right]^{0.5}$.

The RMS differences are given for a fitting with the coefficient of the three $X_{i}(R)$ (case Exp) and for a fitting satisfying self consistency (Theo). The lower panel of Table 3 gives the same RMS difference but for the merged data sample. The three ways of fitting clearly lead to satisfying results. As suggested by Fig. 3, the best fitting is not the same for the eight classes and the four sites. Self consistency constraints obviously do not increase or decrease significantly the quality of the fitting in comparison with the direct use of $X_{i}(R)$ relations. Moreover, the fitting obtained from the relations obtained by merging the data of the four sites of West Africa is not degraded compared with the ones for each site.

For the sample merging all the data of the four sites, the formula generating the DSD, that is (9) with coefficient taken in the line West Africa of Table 2, is:

$N(D)=90 \frac{R^{0.44}}{D} \exp \left[-4.24 \operatorname{Ln}^{2}\left(\frac{D}{R^{0.16}}\right)\right]$.

\section{3. $Z-R$ relations}

Table 4 displays the coefficients of the $Z-R$ relation obtained: (a) by the regression of the couple $Z-R$ observed at each site and for the merged sample and (b) by using $N_{\mathrm{T}}(R)$ and $D_{\mathrm{g}}(R)$ in the moment of $N(D)$, that is Eq. (14). The two sets of coefficients compare very well. The most general observed relation for West Africa is:

$Z=390 R^{1.29}$
Eq. (14), for West Africa, gives:

$Z=373 R^{1.32}$

The radar reflectivity factor difference $[(21)-(22)]$ is of $0.11 \mathrm{~dB}$ and $0.41 \mathrm{~dB}$ for rain rates of 10 and $100 \mathrm{~mm}$ $\mathrm{h}^{-1}$ respectively, that is very close.

\section{Summary and conclusions}

Because $R$ is more easily measured than the drop size distribution and is thus better known around the world, it is useful to be able to write $N(D)$ as a function of $R$ only. In the present paper, the validity of such a parameterisation of $N(D)$ with $R$ is investigated for West Africa. Using a wide sample of data on DSD collected at four sites of West Africa - the two coastal sites of Dakar and Abidjan and the two continental sites of Niamey and Boyélé - the fitting to a lognormal distribution is analysed. The three parameters of the lognormal distribution are first expressed by power function of $R$, namely $X_{i}(R)$, and used in the $N(D)$ expression. The $N(D, R)$ function enables the expression of some useful integral parameters from the moments, notably radar reflectivity factor $\mathrm{Z}$ and rain rate $R$. Writing these expressions raises constraints of self consistency between various expressions of a same parameter. Such self consistency constraints are considered in this paper.

Lognormal distribution parameters $N_{\mathrm{T}}$ and $D_{\mathrm{g}}$ are found to be well represented by a power function of $R$, while $\sigma$ is almost constant. Except for Niamey, probably due to the Sahelian continental character of the corresponding data set, the linear parameters of the power relation are rather homogeneous from one site to another and the values obtained by direct regression are close to those calculated from the self consistency constraints. Scattering is larger for the exponential parameter. $\sigma$ is found to be slightly variable around 1.41 .

The shapes of the observed DSDs for eight classes of $R$ are compared: (a) with curves fitted by using $X_{i}(R)$ relations in the $N(D)$ lognormal expression, (b) with curves fitted from the self consistency relations for each of the four data sets (i.e. each site), and (c) with curves fitted from the self consistency relations computed for the joint data set of West Africa. The three curves are found to fit well the observed DSD for rain rates smaller than $60 \mathrm{~mm} \mathrm{~h}^{-1}$. For $R \geq 60 \mathrm{~mm} \mathrm{~h}^{-1}$, some differences appear but they can probably be in part attributed to the small number of data point available at such high rain rates.

$Z-R$ relations obtained directly from the observed data points and calculated from $N(D, R)$ moments after 
replacing the lognormal parameters by their expressions as function of $R$ are very close, or at least not significantly different, for each site and or for the joint West Africa data set. The $A$ and $b$ parameters are rather homogeneous for West Africa, except for Niamey where drops are larger and fewer than in the other sites as shown in Fig. 2. A "general" $Z-R$ relation usable for West Africa is proposed (relations (21) or (22)).

The conclusion is thus that representing West African DSDs with a lognormal distribution depending only on the $R$ parameter is acceptable and does not introduce any significant error. Introducing self consistency constraints in the DSD fitting does not provide any significant improvement in the results. A "general" expression for $N(D)$ depending on $R$ only and usable for West Africa is proposed (formula 20).

\section{Acknowledgements}

The authors are grateful to all of those who contributed to the collecting of the data set used in this study. Many thanks also to the Agence Universitaire de la Francophonie (AUF) for funding the travel and stay of $\mathrm{AZ}$ at the Laboratoire d'Aérologie in Toulouse and to the FIRMA (Fonds d'Incitation à la Recherche Météorologique en Afrique) program for funding part of the data collection.

\section{References}

Atlas, D., Ulbrich, C.W., 1977. Path and area-integrated rainfall measurement by microwave attenuation in the $1-3 \mathrm{~cm}$ band. $\mathrm{J}$. Appl. Meteorol. 16, 1322-1331.

Atlas, D., Rosenfeld, D., Short, D.A., 1990. The estimation of convective rainfall by area integrals, I. The theoretical and empirical basis. J. Geophys. Res. 95, 2153-2160.

Barrett, E.C., Martin, D.W., 1981. The Use of Satellite Data in Rainfall Monitoring. Academic Press. 340 pp.

Cohen, A.C., 1991. Truncated and censored Samples: Theory and Applications. Marcel Dekker, New York. 312 pp.

Coppens, D., Haddad, Z.S., 2000. Effects of raindrop size distribution variations on microwave brightness temperature calculation. J. Geophys. Res. 105 (D19), 24483-24489.

Crow, E.L., Shimizu, K. Eds, 1988. Lognormal Distribution: Theory and Application. Dekker, New York.

Feingold, G., Levin, Z., 1986. The lognormal fit of raindrop spectra from frontal convective clouds in Israel. J. Clim. Appl. Meteorol. $25,1346-1363$.

Hu, Z., Srivastava, R.C., 1995. Evolution of raindrop size distribution by coalescence, breakup and evaporation: theory and observations. J. Atmos. Sci. 52, 1761-1783.

Huffman, G.I., Adler, R.F., Chang, A., Ferraro, R., Gruber, A., McNab, A., Rudolf, R., Schneider, U., 1997. The global precipitation climatology project (GPCP) combined precipitation data set. Bull. Am. Meteorol. Soc. 78, 5-20.
Iguchi, T., Kozu, T., Meneghini, R., Awaka, J., Okamaoto, K., 2000 Rain-profiling algorithm for the TRMM precipitation radar. J. Appl. Meteorol. 39, 2038-2052.

International Telecommunication Union (ITU), 2001. Characteristics of precipitation for propagation modelling. P Ser., Parts 1 and 2, ITU-R Recomm, vol. 2000, Suppl. 1. 837-3, Geneva.

Joss, J., Waldvogel, A., 1969. Raindrop size distribution and sampling size errors. J. Atmos. Sci. 26, 566-569.

Kebe, C.M.F., Sauvageot, H., Nzeukou, A., 2005. The relation between rainfall and area-time integrals at the transition from an arid to an equatorial climate. J. Clim. 18, 3806-3819.

Lee, G.W., Zawadzki, I., Szyrmer, W., Sempere-Torres, D., Uijlenhaet, R., 2004. A general approach to double-moment normalization of drop size distribution. J. Appl. Meteorol. 43, 264-281.

List, R., 1988. A linear radar reflectivity-rainrate relationship for steady tropical rain. J. Atmos. Sci. 45, 3564-3572.

Marshall, J.S., Palmer, W.M.K., 1948. The distribution of raindrops with size. J. Meteorol. 5, 165-166.

Molnar, P., Burlando, P., 2005. Preservation of rainfall properties in stochastic disaggregation by a simple random cascade model. Atmos. Res. 77, 137-151.

Mueller, E.A., Sims, A.L., 1966. Radar cross sections from drop size spectra. Tech. Rep. ECOM-00032F. Illinois State Water Survey. $110 \mathrm{pp}$.

Nzeukou, A., Sauvageot, H., 2002. Distribution of rainfall parameters near the Coasts of France and Senegal. J. Appl. Meteorol. 41, 69-82.

Nzeukou, A., Sauvageot, H., Ochou, A.D., Kebe, C.M.F., 2004. Raindrop size distribution and radar parameters at Cape Verde. J. Appl. Meteorol. 43, 90-105.

Pasqualucci, F., 1982. The variation of drop size distribution in convective storms: a comparison between theory and measurement. Geophys. Res. Lett. 9, 839-841.

Sall, S.M., Sauvageot, H., 2005. Cyclogenesis off the African Coast: The case of CINDY in August 1999. Mon. Weather Rev. 133, 2803-2813.

Sauvageot, H., 1994. Rainfall measurement by radar: a review. Atmos. Res. 35, 27-54.

Sauvageot, H., Lacaux, J.P., 1995. The shape of averaged drop size distributions. J. Atmos. Sci. 52, 1070-1083.

Sempere-Torres, D., Porra, J.M., Creutin, J.D., 1994. A general formulation for raindrop size distribution. J. Appl. Meteorol. 33, 1494-1502.

Sheppard, B.E., 1990. Effect of irregularities in the diameter classification of raindrop by the Joss-Waldvogel disdrometer. J. Atmos. Ocean. Technol. 7, 180-183.

Sheppard, B.E., Joe, P.I., 1994. Comparison of raindrop size distribution measurements by a Joss-Waldvogel Disdrometer, a PMS 2DG Spectrometer, and a POSS Doppler Radar. J. Atmos. Ocean. Technol. 10, 874-887.

Tokay, A., Kruger, A., Krajewski Gage, W.E., 2001. Comparison of drop size distribution measurements by impact and optical disdrometers. J. Appl. Meteorol. 40, 2083-2097.

Ulbrich, C.W., 1983. Natural variations in the analytical form of the raindrop size distribution. J. Clim. Appl. Meteorol. 22, 1764-1775.

Young, K.C., 1993. Microphysical processes in clouds. Oxford University Press. 427 pp. 